Review

\title{
Central venous catheter-related biofilm infections: An up-to-date focus on meticillin-resistant Staphylococcus aureus ${ }^{\text {is }}$
}

\author{
S. Esposito ${ }^{\mathrm{a}, *}$, S.M. Purrello ${ }^{\text {b }}$, E. Bonnet ${ }^{\mathrm{c}}$, A. Novelli ${ }^{\mathrm{d}}$, F. Tripodi ${ }^{\mathrm{a}}$, R. Pascale ${ }^{\mathrm{a}}$, S. Unal ${ }^{\mathrm{e}}$, G. Milkovich $^{\mathrm{f}}$ \\ a Department of Medicine and Surgery, University of Salerno, Salerno, Italy \\ ${ }^{\mathrm{b}}$ Department of Bio-Medical Sciences, University of Catania, Catania, Italy \\ ${ }^{\mathrm{C}}$ Maladies Infectieuses et Tropicales, Pôle des Spécialités Médicales, CHU de Toulouse, Toulouse, France \\ d Department of Pharmacology, University of Florence, Florence, Italy \\ e Department of Medicine, University of Hacettepe, Ankara, Turkey \\ ${ }^{\mathrm{f}}$ RJM Group, LLC, Placement Strategy Differentiation, Woodbridge, VA, USA
}

\section{A R T I C L E I N F O}

\section{Article history:}

Received 4 January 2013

Received in revised form 25 February 2013

Accepted 5 March 2013

\section{Keywords:}

Central venous catheter

Biofilm

MRSA treatment

Bloodstream-associated infections

\begin{abstract}
A B S T R A C T
Central venous catheters are indispensable for the long-term treatment of seriously and chronically ill patients, but their use is often associated with a variety of complications; indeed, $90 \%$ of primary bloodstream infections are related to patients having a catheter. In studies performed in France, Germany and Italy, meticillin-resistant Staphylococcus aureus (MRSA) accounted for $>50 \%$ of all S. aureus isolates obtained in catheter-related bloodstream infections (CRBSIs). These infections have a serious impact on long-term disability of the patient, a substantial additional financial burden for health systems, and high costs for patients. Decreasing the rate of CRBSIs requires a multidisciplinary approach, including behavioural and educational interventions and the insertion of the correct type of catheter. Although vancomycin remains the cornerstone of empirical therapy for CRBSIs caused by MRSA, combination of different antimicrobials and new approaches are indispensable to enhance the eradication of $S$. aureus biofilms and to manage the patient appropriately.

(c) 2013 International Society for Chemotherapy of Infection and Cancer. Published by Elsevier Ltd. All rights reserved.
\end{abstract}

\section{Contents}

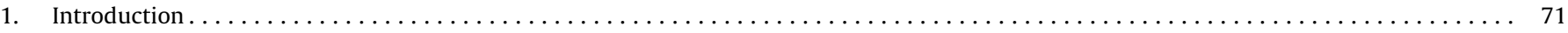

2. Inside catheter-related bloodstream infections: definition, pathogenesis and epidemiology . . . . . . . . . . . . . . . .

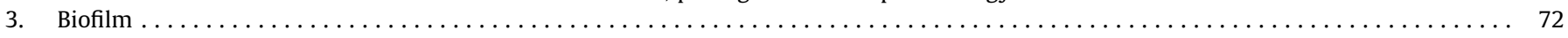

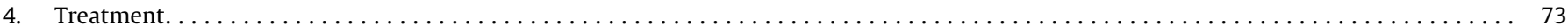

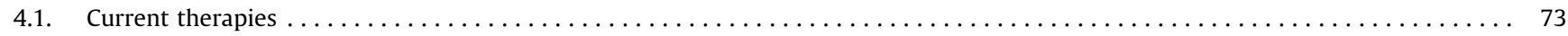

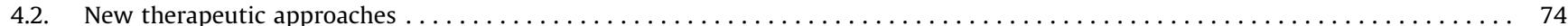

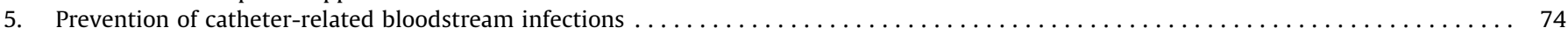

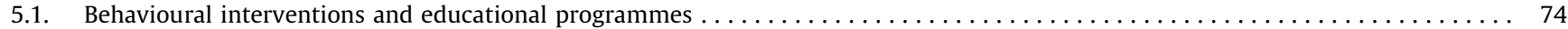

5.2. Choice of the correct central venous catheter (material and antiseptic/antimicrobial-coated catheters) . . . . . . . . . . 75

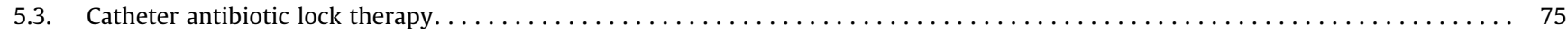

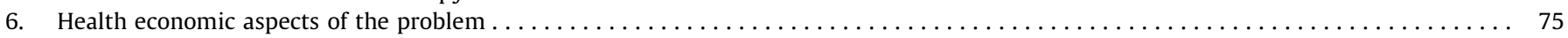

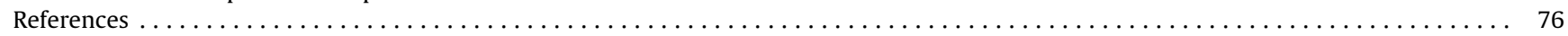

\footnotetext{
This review is based on the proceedings of a meeting held by the International Society of Chemotherapy (ISC), 17-18 March 2012, Naples, Italy.

* Corresponding author. Tel.: +39 3336940183.

E-mail address: silvanoesposito@fastwebnet.it (S. Esposito).
}

\section{Introduction}

Biofilm production is a successful strategy for microbial survival and for the establishment of infection. Since host defence mechanisms and response to antimicrobials are severely prejudiced against bacteria living in the biofilm 'microniche', chronic infections and sepsis related to biofilms represent a major concern in nosocomial settings. 
Central venous catheters (CVCs), which include a variety of vascular access devices with a wide range of clinical applications, are disposed to biofilm infection because they offer a favourable surface for bacterial attachment [1].

Staphylococci are recognised as the most frequent bacteria responsible for biofilm-associated infections, and the involvement in catheter-related infections of meticillin-resistant Staphylococcus aureus (MRSA) has increased the challenge for the healthcare community [2,3].

Upon insertion into the patient, the surface of the catheter is quickly coated with host-derived matrix proteins such as fibrin, fibrinogen, fibronectin, collagen, elastin and laminin [4,5], which serve as scaffolding for bacteria that may have passed the skin barrier. S. aureus can bind to the catheter surface owing to a wide range of cell-wall surface proteins that possess binding domains for the host matrix, and such surface proteins are referred to as microbial surface components recognising adhesive matrix molecules (MSCRAMMs) [6]. Indeed, microorganisms can start to colonise the medical device, forming biofilm, as early as $24 \mathrm{~h}$ after catheter placement [7], and bacteria may then flow into the systemic circulation resulting in a bloodstream infection (BSI).

Thus, although CVCs are indispensable for long-term treatment of seriously and chronically ill patients, their use is often associated with a variety of complications; indeed, $90 \%$ of primary BSIs are related to patients having a central line catheter $[8,9]$.

Although there is debate about whether catheter-related BSIs (CRBSIs) are an independent risk factor for mortality, it is clear that these infections have a serious impact on long-term disability of the patient, a substantial additional financial burden for health systems, and high costs for patients and their families [10-12].

\section{Inside catheter-related bloodstream infections: definition, pathogenesis and epidemiology}

A CRBSI is clinically defined as 'systemic blood infection (bacteraemia) where the same microorganism is retrieved from both the blood and the catheter, without evidence of infection with the identical organism at any other site in the body' [13]. The most common routes for CVC contamination are migration of skin micro-organisms at the catheter insertion site along its surface tract, with subsequent colonisation of the catheter tip, and direct contamination of the catheter hub by contact with hands, contaminated fluid or devices. Less commonly, catheters might be contaminated haematogenously from another focus of infection [14].

From a nationwide surveillance study among 49 US hospitals over a 7-year period, it has been highlighted that the most frequent pathogens for CRBSIs were coagulase-negative staphylococci (31\%), S. aureus (20\%), enterococci (9\%) and Candida spp. [15]. MRSA has become a concern in recent years in the USA, Europe and Japan owing to its increasing rate and, although it appears to have stabilised or even decreased in some European countries (Austria, Cyprus, Estonia, France, Greece, Ireland and the $\mathrm{UK})$, it remains a public health priority since its proportion is still $>25 \%$ in more than one-third of the reporting countries $[16,17]$ and because among the staphylococci, meticillin-resistant isolates have been the most commonly reported as responsible for nosocomial BSIs [18,19].

Although the incidence of CRBSIs has recently decreased as a result of strict prevention efforts, $S$. aureus has been reported as one of the most frequently reported pathogens in intensive care unit (ICU)-acquired infections (21.8\%) in studies performed in France, Germany and Italy $[20,12]$, and MRSA accounted for $>50 \%$ of all $S$. aureus isolates obtained in ICU CRBSIs [21].

\section{Biofilm}

Biofilm formation is a winning move for micro-organisms with respect to the planktonic lifestyle because its enables bacteria to adapt to altered environmental conditions and provides shelter from the host immune system (i.e. phagocytic elimination, opsonisation) and from antimicrobial/antifouling compounds [22].

Generally, biofilm development occurs via a mechanism termed 'quorum sensing' in which the expression of specific signal molecules, called 'autoinducers', is regulated in response to cell density and stressed environmental conditions [23]. $S$. aureus is able to produce a heterogeneous multilayered biofilm using different strategies, including: (i) expression of numerous surface proteins, including Bap, SasG, FnBPs or Spa; (ii) release of extracellular DNA (eDNA); and (iii) expression of the polysaccharide intercellular adhesin (PIA) by the icaADBC operon [24].

Biofilm development is a complex mechanism and includes different stages that can differ from organism to organism. The steps of $S$. aureus biofilm production on intravenous (i.v.) catheters can be summarised as follows: (i) attachment to the catheter surface through electrostatic and hydrophobic forces, platelet binding and shear stress from the fluid environment cause attachment to the host matrix through MSCRAMMs; (ii) intercellular adhesion and growth of the bacteria into sessile multicellular communities through excretion of specific polymers; and (iii) detachment and dissemination of new divided cells to colonise other surfaces and to prevent density-derived starvation within the mature biofilm. Thus, biofilm embedded micro-organisms live in a self-producing exopolymeric matrix or 'slime' that alters the global micro-organism phenotype with respect to growth rate, gene expression and response to external attacks [25].

Nutrients and oxygen permeate the matrix through specific channels and the resulting gradient may generate a population of cells that differ substantially in their metabolism [26]. These cells, named 'persisters', have a low metabolic rate and live in a dormant state attributable to starvation and a low oxygen concentration in the environment, conditions that cause high tolerance to antibiotics [27]. However, persisters are not mutants; indeed, re-culturing of persisters produces a wild-type population with a new population of persisters [28,29]. In other words, persisters are stationary phase cells with increased resistance to killing owing to slow growth produced not only in biofilms but also in stationary phase planktonic populations [30].

Moreover, antibiotic penetration through the biofilm is limited by the exopolysaccharide matrix that acts like a diffusion barrier, limiting the antibiotic uptake rate and also reacting with these molecules [25]. For a long time it appeared that molecular weight was a limiting factor for antibiotic penetration into biofilms, however recent studies have demonstrated that the molecular dimensions of antibiotics have no significant relevance [31,32]. Indeed, in an in vitro study by Stewart et al., daptomycin, one of the antibiotics with a higher molecular weight, was confirmed to have freely diffusive penetration into a large, dense cluster of staphylococcal biofilms [33].

Thus, from a clinical point of view, the hallmark of biofilmembedded micro-organisms is their resistance to large doses of traditional antimicrobial agents; they can actually be $100-1000-$ fold less susceptible than their planktonic counterparts [34]. For this reason, treatment of CRBSIs, which is regulated by standardised antimicrobial susceptibility tests performed with planktonic cells, can have an unsuccessful outcome and often relies on removal of the catheter [22]. 


\section{Treatment}

Although there is no unanimously accepted clinical pathway for the management of CRBSIs, several guidelines and recommendations have recently been published [34-37] and, in general, treatment of these infections should include oral or i.v. antibiotics or an antibiotic lock technique (ALT) and removal and re-insertion of the CVC in the case of $S$. aureus infection.

It is important to underline that the vast majority of $S$. aureus biofilm infections require long-term therapy and so it is crucial to take into account toxicities and drug interactions when selecting a specific regimen.

The ability of an antibiotic to eradicate MRSA embedded in biofilm depends on many factors such as its molecular mass, net charge, permeability coefficient and bactericidal activity. Antibiotics of low molecular weight are likely to diffuse more efficiently into the biofilm [38].

So, when considering staphylococcal biofilm treatment options, the ideal therapy would have several characteristics:

- bactericidal activity against slow-growing, stationary phase-like cells;

- low rate of resistance development;

- straightforward administration of the therapy to patients, with few side effects; and

- broad efficacy against all staphylococci and polymicrobial biofilm infections.

Even if the catheter has been removed and a new one has been inserted, an antibiotic regimen including antibiofilm activity must be considered. Indeed, colonisation of the new catheter by biofilm fragments dislodged from the one that has been removed is possible.

\subsection{Current therapies}

For the treatment of serious MRSA device-related infections, vancomycin remains the cornerstone of empirical therapy, but in the most recent 10 years $S$. aureus minimum inhibitory concentrations (MICs) to vancomycin have increased from $0.25 \mathrm{mg} / \mathrm{L}$ to $2 \mathrm{mg} / \mathrm{L}$, associating its use with several therapeutic failures.

Guidelines indicate that patients with complicated MRSA infections should receive 4-6 weeks of vancomycin therapy, except those with a vancomycin MIC $>2 \mathrm{mg} / \mathrm{L}$, who should instead receive daptomycin or linezolid depending on susceptibility data [38].

Vancomycin acts by binding to the cell wall peptidoglycan chains and therefore preventing the cross-linking step during cell wall synthesis. This effect leads to a weakened cell wall, slowing growth and bacterial death [39].

Although vancomycin is considered bactericidal, its timedependent mode of action, the i.v. administration required and the frequent side effects are serious limitations of this drug that can lead to longer hospital stays and higher costs for the institution [40].

Moreover, recently there have been conflicting results on the use of vancomycin monotherapy in the treatment of biofilmembedded MRSA [41-43]. Rose and Poppens demonstrated that vancomycin exhibited bactericidal activity towards planktonic MRSA cells at low levels $(1 \mu \mathrm{g} / \mathrm{mL})$, but the MIC increased four- to eight-fold in a biofilm susceptibility assay, suggesting its use in combination with rifampicin or tigecycline [44]. In fact, also in other studies it has been shown that vancomycin efficacy increases in combination with other antibiotics (rifampicin, gentamicin, clindamycin), leading to better penetration of the drug into the depth of the biofilm $[45,46]$.
In the face of emerging resistance to vancomycin and other glycopeptides, daptomycin is being used as an alternative first-line therapy against biofilm-embedded MRSA.

Daptomycin, a cyclic lipopeptide, is bactericidal towards log phase, stationary phase and metabolically inert Gram-positive bacteria owing to insertion of its lipophilic tail into the cell membrane, resulting in membrane depolarisation and cell death. In a study by Mascio et al., daptomycin demonstrated bactericidal activity against log phase $S$. aureus cells at low concentrations ( $2 \mathrm{mg} / \mathrm{L}$ ) and against stationary phase cells at a higher concentration $(100 \mathrm{mg} / \mathrm{L})$ [47].

For the treatment of staphylococcal biofilm infections, daptomycin alone is more effective than other monotherapies. An in vitro study of 12 MRSA clinical isolates showed that daptomycin was the most effective of five antibiotics tested (compared with clindamycin, linezolid, tigecycline and vancomycin) at killing cells within biofilms; in fact, although total killing of biofilm cells was not achieved, daptomycin treatment eliminated 96\% of biofilmassociated bacteria [43].

In combination therapy, daptomycin treatment with rifampicin or gentamicin has shown conflicting results, but its clinical use has proven successful against several forms of biofilm infections $[48,49]$. Finally, in a rat model study by Van Praagh et al., combined daptomycin ALT and systemic dosing resulted in clearance of $S$. aureus CVC-related infection after two daily ALT treatments [50].

Oxazolidinones inhibit ribosome function and prevent protein synthesis by targeting the assembly of ribosomal subunits. Linezolid is the only oxazolidinone approved for clinical use [51] and has encouraging properties, including broad-spectrum activity against Gram-positive bacteria, good tissue distribution and penetration, and bioavailability. Moreover, among the antibiotics used for the treatment of invasive MRSA infections, linezolid is one of the few that can be taken orally. Linezolid has demonstrated activity against biofilms both in in vitro and in vivo model systems. In a rabbit model of $S$. aureus endocarditis, linezolid cleared biofilm vegetations after 5 days of treatment when administered at high doses that maintained the blood level above the MIC [52], whilst in another recent study linezolid exhibited bactericidal activity in combination with rifampicin and prevented the development of infection at secondary sites [53].

Linezolid was also tested on staphylococcal biofilms utilising an in vitro pharmacokinetic model in which the biomass was developed on a cellulose filter and this was perfused with a solution containing the antibiotic. This study highlighted that linezolid was very effective at clearing biofilm if the infected device was exposed to the antibiotic for longer time periods, whilst success with short-term exposure varied and might be dependent on the type of infected device being treated [54]. In addition, a model of ALT gave conflicting results, showing that the amount of biofilm remaining after 5 days of linezolid exposure was similar to negative controls [55]. Instead, clinical use and combination therapy of linezolid to treat staphylococcal biofilm infections has been shown to be promising. In a study of prosthetic joint infections, treatment of patients ( 49 total) with combined therapy of linezolid and rifampicin cleared infection with a success rate of nearly $70 \%$ without implant removal [56].

Rifampicin has the capacity to kill metabolically dormant sessile bacteria, typical of biofilm, and has the ability to effectively penetrate the biofilm layer preventing its formation within only minutes of treatment. It has bactericidal activity and targets the bacterial RNA polymerase, inhibiting RNA synthesis. Numerous examples of in vitro studies, in vivo animal models of infection, and clinical studies demonstrated the efficacy of rifampicin in treating staphylococcal implant infections [57]. In one study evaluating antibiotics within ALT, co-administration of rifampicin with other 
antibiotics resulted in enhanced eradication of MRSA biofilms more than any monotherapy.

The same study demonstrated that daptomycin, minocycline and tigecycline were more effective in decreasing viable biofilmembedded MRSA after $24 \mathrm{~h}$ of exposure than linezolid or vancomycin. Addition of rifampicin to vancomycin or linezolid was synergistic against biofilm-embedded MRSA [55]. In addition to its bactericidal and fast-acting properties, rifampicin has good pharmacokinetic properties, achieving penetration into diverse tissue sites. It is lipid soluble, facilitating passage through biological membranes, perhaps improving its biofilm-penetrating capability.

Fosfomycin has been characterised in previous in vitro studies as an effective antibacterial against MRSA [58,59]; however, no in vivo studies on the effects of fosfomycin on biofilm-embedded MRSA have been published.

A recent study evaluated the activity of several anti-MRSA compounds, alone and in combination with fosfomycin, on bacterial colony counts in biofilm and demonstrated that fosfomycin enhances the activity of linezolid, minocycline, vancomycin and teicoplanin on MRSA in biofilm, even more than rifampicin combination regimens. The low molecular weight of fosfomycin may partially explain its enhanced antibacterial activity against biofilm-embedded micro-organisms [60].

\subsection{New therapeutic approaches}

Essential antimicrobial targets for inhibition of biofilm formation or for eradication of mature biofilm are not only the bacteria themselves but also destruction of biofilm matrix and interference with the biofilm signalling system [61].

Whilst antibiotics and novel derivatives have been the mainstay of empirical therapy, many efforts have been made to design more innovative therapeutic options such as nanosilver, the cytokine interleukin-12, nitric oxide or antistaphylococcal phages [62-65]. However, the clinical utility of these agents has yet to be demonstrated. One strategy for controlling biofilm growth is to weaken its structure by targeting the matrix components, which leads to dispersal of bacteria and consequently to a greater susceptibility to antibiotics [66].

\section{Prevention of catheter-related bloodstream infections}

Decreasing the rate of CRBSIs requires a comprehensive and multidisciplinary approach, including behavioural and educational interventions of the hospital staff as well as the use of new technologies. There are several guidelines providing recommendations for the preventions of CRBSIs [67,68]. These guidelines examine the usefulness of various practices such as the choice of CVC, site of insertion, observance of an adequate aseptic technique, care and replacement of the catheter, and the choice of appropriate antibiotic therapy.

An initial and crucial step in preventing CRBSIs is to weight and consider the risks and benefits of using a CVC in order to avoid unnecessary placements; indeed, in a recent hospital survey it was calculated that among a total of 378 CVCs inserted in 292 patients, accounting for 2704 catheter-days, 130 catheter-days (4.8\%) were unnecessary, with a higher proportion in non-ICU settings (6.6\%) [69]. Various risk factors involving insertion or catheter handling have been described in the literature. Such risk factors have been named 'modifiable' [70] because they are the optimal candidates for CRBSI prevention strategies (Table 1 ).

These factors are as follows. (i) Aseptic measures: hygiene and aseptic techniques during placement, management and removal of catheters are essential in preventing infection. (ii) CVC duration: the overall proportion of CRBSIs is actually higher in long-term
Table 1

Modifiable risk factors for catheter-related bloodstream infections (CRBSIs).

\begin{tabular}{ll}
\hline Aseptic measures & $\begin{array}{l}\text { Risk of infection declines following standardisation } \\
\text { of aseptic care } \\
\text { Length of stay increases the risk of CRBSIs more } \\
\text { than other risk factors } \\
\text { Insertion site increases the infection risk relative } \\
\text { to the density of local skin flora and the chance } \\
\text { of developing thrombophlebitis } \\
\text { CVCs can be chosen with regard to material and } \\
\text { whether or not to use an antimicrobial/ } \\
\text { Type of catheter }\end{array}$ \\
Nurse-to-patient ration & $\begin{array}{l}\text { Education and training of nurses are critical for } \\
\text { the prevention of CRBSIs }\end{array}$ \\
\hline
\end{tabular}

CVC, central venous catheter.

devices, and the length of stay in ICU settings increases the risk of CRBSI more than other risk factors [71]. (iii) CVC insertion site [72]: the site at which a catheter is placed influences the subsequent possibility for a catheter-related infection risk in terms of density of local skin flora and chance of developing thrombophlebitis. In some retrospective studies, catheters inserted into an internal jugular vein have usually been associated with a higher risk of CRBSI than those inserted into a subclavian site [73]. Femoral catheters have, on the other hand, been associated with a higher risk for venous thrombosis than internal jugular or subclavian catheters [74]. (iv) Introduction of the correct type of catheter. And (v) high workload: an optimum nurse-to-patient ratio has been correlated with a lower CRBSI rate [70].

\subsection{Behavioural interventions and educational programmes}

Performing hand hygiene procedures before insertion or maintenance of a catheter is the first and most important basic rule of hygiene and, combined with proper aseptic techniques during catheter manipulation, provides protection against infection.

Reports in past years have clearly demonstrated that the risk of infection declines following standardisation of aseptic care [75-77]. Maximal sterile barriers, which include wearing a mask, cap, sterile gown and sterile gloves and covering the insertion site with a large surgical drape, were shown to be effective either alone or as a part of a multimodal CRBSI prevention strategy. These CRBSI bundles were, as reported in many published studies, very efficient and reduced the CRBSI incidence density, reported as the number of CRBSI episodes per 1000 catheterdays, by $\geq 70 \%$ [78].

Education, training and staffing are critical for the prevention of CRBSIs. Well organised programmes include education of healthcare personnel and periodically assessing knowledge of the guidelines for all personnel involved in the insertion and maintenance of catheters.

Recently, an educational programme demonstrated that a 1day course on basic infection control practises and a demonstration of insertion both of arterial and CVCs illustrated to beginning post-graduate year 1 (PGY-1) physicians resulted in a significant reduction in CRBSI and primary BSIs from 3.3 to 2.4 per 1000 CVCdays [75]. Other recent studies demonstrated that specialised 'IV teams' have shown clear helpfulness in reducing the CRBSI incidence, associated complications and overall costs $[79,80]$.

Although educational programmes have an impact on the healthcare institution and may not be sustainable over time, hospitals should try to provide clear guidelines for catheter insertion and maintenance and ensure their observance to maintain a high level of awareness of standard procedures [81].

The benefits of preventing CRBSIs are numerous, and if we think that a large proportion of them are preventable, it is clear that a 
strong attempt has to be made from the healthcare community to face this problem.

\subsection{Choice of the correct central venous catheter (material and antiseptic/antimicrobial-coated catheters)}

In recent years, significant efforts have been made to design new catheters aimed at reducing the risk of CRBSIs.

Major choices for the clinician when inserting a CVC are regarding its material and whether or not to use an antimicrobial/ anti-infective-coated catheter.

Regarding the material, important considerations have been made on this topic, i.e. polytetrafluoroethylene (Teflon ${ }^{\mathbb{R}}$ ) or polyurethane catheters have been associated with fewer infectious complications than catheters made of polyvinyl chloride or polyethylene [82]. Catheter material is critical in the prevention of CRBSIs; it should be biocompatible/biostable, chemically neutral, and drug/sterilisation proof [83].

The underlying principle for the use of a coated CVC is the possibility of modifying the catheter surface to minimise bacterial adhesion and consequently biofilm formation. The decision to insert an antibiotic-coated CVC has to be taken in view of the single risk factors for an infection of a given patient and overall rates of CRBSI for a specific hospital. Following the US Centers for Disease Control and Prevention (CDC) Healthcare Infection Control Practices Advisory Committee guidelines, coated catheters should be inserted in adult patients if the CVC is to remain place for $>5$ days as well as in institutions with high CRBSI rates [67].

Coated CVCs are available with different impregnated materials: (i) chlorhexidine and silver sulfadiazine (CSS); (ii) minocycline-rifampicin (MR); and (iii) silver in a carbon/ platinum (SPC) matrix. One meta-analysis and one randomised controlled trial have demonstrated that first-generation CSS catheters, which are coated only on the external luminal surface, are associated with a reduced risk of CRBSI compared with standard non-coated catheters. In fact, chlorhexidine and silver salts act synergistically, disrupting the cytoplasmic membrane and increasing silver uptake, which is extremely toxic for microorganisms [84,85].

Second-generation CSS catheters are now available with chlorhexidine also coating the internal surface, but a limited number of control trials have been carried out [86,87]. CSS catheters are more expensive than standard catheters, however there is a debate on the real cost saving per catheter despite adherence to other preventive strategies; one study showed that CSS catheters could lead to a cutback per catheter in settings with a high CRBSI rate ranging between US\$391 and US\$68 [88].

MR CVCs have broad-spectrum activity and have been studied both in vitro and in vivo in randomised clinical trials, which have demonstrated that these catheters are effective against biofilmproducing bacteria and are associated with a lower rate of CRBSIs $[89,90]$.

Compared with first-generation CSS catheters, MR CVCs have also been found to be related to lower CRBSI rates, but their evaluation against second-generation CSS CVCs has to be further investigated. Although no MR-resistant organisms were reported in several studies [91-93], there are still some concerns about the potential for development of rifampicin-resistant bacteria. Finally, several studies revealed that these catheters are associated with superior cost saving compared with standard catheters [94] and with first-generation CSS CVCs [95,96].

SPCs are only available in the USA and some studies have evaluated their effectiveness against uncoated or MR catheters, but their association with a lower rate of CRBSIs has not yet been clearly demonstrated [97].

\subsection{Catheter antibiotic lock therapy}

Given the cost, difficulty and complication associated with the removal of a long-term CVC, some guidelines have suggested the use of catheter ALT for the prevention of CRBSI and salvage of the CVC in high-risk patients [38,98].

ALT consists of the 'lockage' of a specified antibiotic in the CVC when the catheter is not in use (generally $18-24 \mathrm{~h}$ ) with or without heparin at concentrations 100-1000 times higher than the target micro-organism's MIC measured for systemic therapy. The recommended duration of ALT is 2 weeks [99].

Ideally, the use of concentration-dependent killing antibiotics is optimal, rather than time-dependent killing antibiotics such as glycopeptides, so that minimum biofilm eradicating concentrations can be achieved without dependence on dwell time.

Whilst ALT has been shown to decrease the rate of CRBSIs in haemodialysis patients with long-term catheters, the benefit in ICU patients with short-term CVCs is less clear [98].

More rigorous clinical studies are needed before antibiotic lock solution can be universally recommended, in part because of the concern for the generation of multidrug-resistant micro-organisms [99]. Choosing the correct ALT prevention treatment is crucial because the agent selected has to be able to penetrate the thick biofilm matrix and act against microbial cells growing in a stationary-like state.

\section{Health economic aspects of the problem}

Use of a medical device is the greatest exogenous predictor of healthcare-associated infection (HAI), and CRBSIs, together with surgical-site infections, ventilator-associated pneumonia and catheter-associated urinary tract infections, account for approximately three-quarters of HAIs [100].

Although global estimations of HAIs are not available, by integrating data from several published studies it is clear that hundreds of millions of patients are affected every year worldwide, with the burden of disease much higher in low- and middleincome countries [101].

Recent data regarding the costs and numbers of HAIs are available from the European Centre for Disease Prevention and Control (ECDC), which has calculated that HAIs involve 4.1 million patients annually in the European Union; furthermore, as reported by the World Health Organisation (WHO) in 2011, only direct costs associated with HAIs account for about $€ 7$ billion annually $[16,18]$.

In particular, it is important to underline that MRSA accounts for $44 \%$ ( $n=171200)$ of these HAIs and causes $22 \%(n=5400)$ extra deaths and $41 \%$ ( $n=1050000)$ extra days of hospitalisation, with extra attributable in-hospital costs of ca. $€ 380$ million annually [16].

The CDC has recently estimated the annual hospital costs of HAIs in the USA to be between US\$28 billion and US\$45 billion per year [34], and MRSA-associated costs are ca. US\$10 billion/year, occurring in 31.3/100 000 hospitalised people, $20 \%$ of which result in fatal infections [102].

As the use of CVCs has increased over the last years, so the number of CRBSIs has risen [103]. It has been estimated that in the USA over 5 million medical devices are used per annum and ca. $4 \%$ of patients develop CRBSI; the number of deaths has been estimated at $12.5 \%$, equating to $0.5 \%$ of CVC insertions [104]. The problem is even more serious among ICUs where in the ca. 250000 CRBSIs occurring every year in the USA, ca. 28000 lead to deaths in ICU patients only, with an annual cost of up to US\$2.3 billion [105].

Furthermore, as reported by Tacconelli et al. in a study performed among four European countries, additional length of hospital stay per CRBSI episode varies between 4 days and 14 days, 
with additional associated costs from $€ 4200$ to $€ 13030$ per episode, representing an annual cost to the national healthcare systems of between $€ 53.9$ million in the UK and $€ 130$ million in France [106]. Nevertheless, it should be underlined that costeffectiveness studies might be of limited value because sometimes they lack precision and do not have large economic perspectives, resulting in poor quality reports. For instance, cost reports of a single episode of CRBSI in the literature vary between US\$3000 and US\$56 000, hence data from different types of analyses must be interpreted with caution $[10,11,107]$.

Usually three key components should be included in a complete global socioeconomic cost analysis of HAIs: direct medical costs that directly impact hospital finances; indirect costs (related to productivity); and non-medical costs or intangible costs related, e.g. to the diminished quality of life of the patient. In a 2-year, prospective, case-control study, Tarricone et al. evaluated direct healthcare costs of central line-associated BSIs according to a microcosting approach and found not only that central lineassociated BSIs pose a significant increase in utilisation of hospital resources but also that the use of innovative and relatively simple technologies, in this case closed infusion containers, can significantly reduce the incidence of HAIs without additional weight on the overall hospital budget [108].

From these numbers, not only the magnitude of the CRBSI burden worldwide but also the need to urgently establish a reliable system for healthcare-associated infection and CRBSI surveillance to gather data on the actual numbers and costs as frequently as possible is clear. Moreover, evaluation of the key determinants of CRBSIs is an essential step to identify strategies and measures for prevention. In fact, robust evidence supports that CRBSIs can be prevented and the burden reduced by as much as 50\% [109].

\section{Funding}

None.

\section{Competing interests}

None declared.

\section{Ethical approval}

Not required.

\section{References}

[1] Davey ME, O’Toole GA. Microbial biofilms: from ecology to molecular genetics. Microbiology and Molecular Biology Reviews 2000;64:847-67.

[2] Durante Mangoni E, Carbonara S, Iacobello C, Tripodi MF, Carretta A, Caprioli $\mathrm{V}$, et al. Management of infections from cardiac implantable electronic devices: recommendations from a study panel. Infez Med 2011;19:207-23 [in Italian].

[3] National Nosocomial Infections Surveillance (NNIS) system report. Atlanta, GA: US Centers for Disease Control and Prevention, US Department for Health and Human Services; 1998.

[4] Mehall JR, Saltzman DA, Jackson RJ, Smith SD. Fibrin sheath enhances central venous catheter infection. Critical Care Medicine 2002;30:908-12.

[5] Casey AL, Mermel LA, Nightingale P, Elliott TS. Antimicrobial central venous catheters in adults: a systematic review and meta-analysis. Lancet Infectious Diseases 2008;8:763-76.

[6] Foster TJ, Hook M. Surface protein adhesins of Staphylococcus aureus. Trends in Microbiology 1998;6:484-8.

[7] Raad I, Costerton W, Sabharwal U, Sacilowski M, Anaissie E, Bodey GP. Ultrastructural analysis of indwelling vascular catheters: a quantitative relationship between luminal colonization and duration of placement. Journal of Infectious Diseases 1993;168:400-7.

[8] Marvaso A. Central venous catheter-related infections. Infez Med 2000; 8:202-10 [in Italian].

[9] Aschbacher R, Picon B, Wootton M, Davies L, Binazzi R, Pike R, et al. Molecular epidemiology of methicillin-resistant Staphylococcus aureus from bacteraemia in northern Italy. Infez Med 2012;20:256-64.
[10] Halton K, Graves N. Economic evaluation and catheter-related bloodstream infections. Emerging Infectious Diseases 2007:13:815-23.

[11] Pittet D, Tarara D, Wenzel RP. Nosocomial bloodstream infection in critically ill patients. Excess length of stay, extra costs, and attributable mortality. Journal of the American Medical Association 1994;271:1598-601.

[12] De Gaetano Donati K, Tacconelli E, Tumbarello M, Bertagnolio S, Pittiruti M, Leone F, et al. Central venous catheter-related sepsis: one year experience in a large university hospital. Infez Med 1999;7:227-30 [in Italian].

[13] Walz JM, Memtsoudis SG, Heard SO. Prevention of central venous catheter bloodstream infections. Journal of Intensive Care Medicine 2010;25:131-8.

[14] Weber DJ, Rutala WA. Central line-associated bloodstream infections: prevention and management. Infectious Disease Clinics of North America 2011; 23:77-102.

[15] Wisplinghoff $H$, Bischoff T, Tallent SM, Seifert H, Wenzel RP, Edmond MB. Nosocomial bloodstream infections in US hospitals: analysis of 24,179 cases from a prospective nationwide surveillance study. Clinical Infectious Diseases 2004;39:309-17.

[16] European Centre for Disease Prevention and Control (ECDC). Antimicrobial resistance surveillance in Europe 2009. Annual report of the European Antimicrobial Resistance Surveillance Network (EARS-Net). Stockholm, Sweden: ECDC; 2010.

[17] Barbarini D, Fumagalli P, Marone P, Marzani FC, Braschi A, Emmi V, et al. Methicillin-resistant Staphylococcus aureus (MRSA) in an intensive care unit: a one-year survey. Infez Med 2001;9:237-45 [in Italian].

[18] Diekema DJ, Pfaller MA, Jones RN, SENTRY Participants Group. Age-related trends in pathogen frequency and antimicrobial susceptibility of bloodstream isolates in North America: SENTRY Antimicrobial Surveillance Program, 1997-2000. International Journal of Antimicrobial Agents 2002;20: 412-8.

[19] Cetin BD, Hasman H, Ozcan N, Gündüz A, Harmankaya O, Seber E. Epidemiology and etiology of catheter-related nosocomial infections in a Turkish hospital. Infez Med 2005;13:152-9.

[20] World Health Organization. Report on the burden of endemic health careassociated infection worldwide. Geneva, Switzerland: WHO; 2011.

[21] Burton DC, Edwards JR, Horan TC, Jernigan JA, Fridkin SK. Methicillin-resistant Staphylococcus aureus central line-associated bloodstream infections in US intensive care units, 1997-2007. Journal of the American Medical Association 2009;301:727-36.

[22] Stewart PS, Costerton JW. Antibiotic resistance of bacteria in biofilms. Lancet 2001;358:135-8.

[23] Kong KF, Vuong C, Otto M. Staphylococcus quorum sensing in biofilm formation and infection. International Journal of Medical Microbiology 2006;296:133-9.

[24] Archer NK, Mazaitis MJ, Costerton JW, Leid JG, Powers ME, Shirtliff ME. Staphylococcus aureus biofilms: properties, regulation, and roles in human disease. Virulence 2011;2:445-59.

[25] Donlan RM, Costerton JW. Biofilms: survival mechanisms of clinically relevant microorganisms. Clinical Microbiology 2002;15:167-93.

[26] Rani SA, Pitts B, Beyenal H, Veluchamy RA, Lewandowski Z, Davison WM, et al. Spatial patterns of DNA replication, protein synthesis, and oxygen concentration within bacterial biofilms reveal diverse physiological states. Journal of Bacteriology 2007;189:4223-33.

[27] Lewis K. Persister cells. Annual Review of Microbiology 2010;64:357-72.

[28] Bigger JW. Treatment of staphylococcal infections with penicillin. Lancet 1944;ii:497-500.

[29] Brooun AS, Liu S, Lewis K. A dose-response study of antibiotic resistance in Pseudomonas aeruginosa biofilms. Antimicrobial Agents and Chemotherapy 2000;44:640-6.

[30] Spoering AL, Lewis K. Biofilms and planktonic cells of Pseudomonas aeruginosa have similar resistance to killing by antimicrobials. Journal of Bacteriology 2001;183:6746-51.

[31] Corbin A, Pitts B, Parker A, Stewart PS. Antimicrobial penetration and efficacy in an in vitro oral biofilm model. Antimicrobial Agents and Chemotherapy 2011;55:3338-44.

[32] Stefani S, Esposito S. Daptomycin, the first cydal antibiotic of a new class active against Gram positive pathogens. Infez Med 2006;14:179-96 [in Italian].

[33] Stewart PS, Davison WM, Steenbergen JN. Daptomycin rapidly penetrates a Staphylococcus epidermidis biofilm. Antimicrobial Agents and Chemotherapy 2009;53:3505-7.

[34] Mermel LA, Allon M, Bouza E, Craven DE, Flynn P, O’Grady NP, et al. Clinical practice guidelines for the diagnosis and management of intravascular catheter-related infection: 2009 update by the Infectious Diseases Society of America. Clinical Infectious Diseases 2009;49:1-45.

[35] Bouza E, Burillo A, Munoz P. Empiric therapy for intravenous central line infections and nosocomially-acquired acute bacterial endocarditis. Critical Care Clinics 2008;24:293-312.

[36] Sabatier C, Ferrer R, Vallés J. Treatment strategies for central venous catheter infections. Expert Opinion on Pharmacotherapy 2009;10:2231-43.

[37] Aslam S. Effect of antibacterials on biofilms. American Journal of Infection Control 2008;36(S175):e9-11.

[38] Mermel LA, Farr BM, Sherertz RJ, Raad II, O’Grady N, Harris JS. Guidelines for the management of intravascular catheter-related infections. Clinical Infectious Diseases 2001;32:1249-72.

[39] Abbanat D, Macielag M, Bush K. Novel antibacterial agents for the treatment of serious Gram-positive infections. Expert Opinion on Investigational Drugs 2003;12:379-99. 
[40] Chambers HF, Deleo FR. Waves of resistance: Staphylococcus aureus in the antibiotic era. Nature Reviews Microbiology 2009;7:629-41.

[41] Petersen PJ, Bradford PA, Weiss WJ, Murphy TM, Sum PE, Projan SJ. In vitro and in vivo activities of tigecycline (GAR-936), daptomycin, and comparative antimicrobial agents against glycopeptide-intermediate Staphylococcus aureus and other resistant Gram-positive pathogens. Antimicrobial Agents and Chemotherapy 2002;46:2595-601.

[42] Wiederhold P, Coyle EA, Raad II, Randall A, Russell E, Nathan L. Antibacterial activity of linezolid and vancomycin in an in vitro pharmacodynamic model of Gram-positive catheter-related bacteraemia. Journal of Antimicrobial Chemotherapy 2005;55:792-5.

[43] Smith K, Perez A, Ramage G, Gemmell CG, Lang S. Comparison of biofilmassociated cell survival following in vitro exposure of meticillin-resistant Staphylococcus aureus biofilms to the antibiotics clindamycin, daptomycin, linezolid, tigecycline and vancomycin. International Journal of Antimicrobial Agents 2009;33:374-8.

[44] Rose W, Poppens PT. Impact of biofilm on the in vitro activity of vancomycin alone and in combination with tigecycline and rifampicin against Staphylococcus aureus. Journal of Antimicrobial Chemotherapy 2009;63:485-8.

[45] Olson ME, Slater SR, Rupp ME, Fey PD. Rifampicin enhances activity of daptomycin and vancomycin against both a polysaccharide intercellular adhesion (PIA)-dependent and -independent Staphylococcus epidermidis biofilm. Journal of Antimicrobial Chemotherapy 2010;65:2164-71.

[46] Salem AH, Elkhatib WF, Noreddin AM. Pharmacodynamic assessment of vancomycin-rifampicin combination against methicillin resistant Staphylococcus aureus biofilm: a parametric response surface analysis. Journal of Pharmacy and Pharmacology 2011;63:73-9.

[47] Mascio CT, Alder JD, Silverman JA. Bactericidal action of daptomycin against stationary-phase and nondividing Staphylococcus aureus cells. Antimicrobial Agents and Chemotherapy 2007;51:4255-60.

[48] John AK, Baldoni D, Haschke M, Rentsch K, Schaerli P, Zimmerli W, et al. Efficacy of daptomycin in implant-associated infection due to methicillinresistant Staphylococcus aureus: importance of combination with rifampin. Antimicrobial Agents and Chemotherapy 2009;53:2719-24.

[49] LaPlante KL, Woodmansee S. Activities of daptomycin and vancomycin alone and in combination with rifampin and gentamicin against biofilm-forming methicillin-resistant Staphylococcus aureus isolates in an experimental model of endocarditis. Antimicrobial Agents and Chemotherapy 2009;53:3880-6.

[50] Van Praagh ADG, Li T, Zhang S, Arya A, Chen L, Zhang X, et al. Daptomycin antibiotic lock therapy in a rat model of staphylococcal central venous catheter biofilm infections. Antimicrobial Agents and Chemotherapy 2011; 55:4081-9.

[51] Moellering RC. Linezolid: the first oxazolidinone antimicrobial. Annals of Internal Medicine 2003:138:135-42.

[52] Oramas-Shirey MP, Buchanan LV, Dileto-Fang CL, Dailey CF, Ford CW, Batts $\mathrm{DH}$, et al. Efficacy of linezolid in a staphylococcal endocarditis rabbit model. Journal of Antimicrobial Chemotherapy 2001;47:349-52.

[53] Tsaganos T, Skiadas I, Koutoukas P, Adamis T, Baxevanos N, Tzepi I, et al. Efficacy and pharmacodynamics of linezolid, alone and in combination with rifampicin, in an experimental model of methicillin-resistant Staphylococcus aureus endocarditis. Journal of Antimicrobial Chemotherapy 2008;62:381-3.

[54] Gander S, Hayward K, Finch R. An investigation of the antimicrobial effects of linezolid on bacterial biofilms utilizing an in vitro pharmacokinetic model. Journal of Antimicrobial Chemotherapy 2002;49:301-8.

[55] Raad I, Hanna H, Jiang Y, Dvorak T, Reitzel R, Chaiban G, et al. Comparative activities of daptomycin, linezolid, and tigecycline against catheter-related methicillin-resistant Staphylococcus bacteremic isolates embedded in biofilm. Antimicrobial Agents and Chemotherapy 2007;51:1656-60.

[56] Gómez J, Canovas E, Baños V, Martínez L, García E, Hernández-Torres A, et al Linezolid plus rifampin as a salvage therapy in prosthetic joint infections treated without removing the implant. Antimicrobial Agents and Chemotherapy 2011;55:4308-10.

[57] Zimmerli W, Trampuz A, Ochsner PE. Prosthetic-joint infections. New England Journal of Medicine 2004;351:1645-54

[58] Popovic M, Steinort D, Pillai S, Joukhadar C. Fosfomycin: an old, new friend? European Journal of Clinical Microbiology and Infectious Diseases 2010;29: 127-42.

[59] Grif K, Dierich MP, Pfaller K, Miglioli PA, Allerberger F. In vitro activity of fosfomycin in combination with various antistaphylococcal substances. Journal of Antimicrobial Chemotherapy 2001;48:209-17.

[60] Tang HJ, Chen CC, Cheng KC, Toh HS, Su BA, Chiang SR, et al. In vitro efficacy of fosfomycin-containing regimens against methicillin-resistant Staphylococcus aureus in biofilms. Journal of Antimicrobial Chemotherapy 2012; 67:944-50.

[61] Boles BR, Horswill AR. Staphylococcal biofilms disassembly. Trends in Microbiology 2011;19:449-55.

[62] Alt V, Bechert T, Steinrücke P, Wagener M, Seidel P, Dingeldein E, et al. An in vitro assessment of the antibacterial properties and cytotoxicity of nanoparticulate silver bone cement. Biomaterials 2004;25:4383-91.

[63] Boyce BM, Lindsey BA, Clovis NB, Smith ES, Hobbs GR, Hubbard DF, et al. Additive effects of exogenous IL-12 supplementation and antibiotic treatment in infection prophylaxis. Journal of Orthopaedic Research 2012;30: 196-202.

[64] Friedman A, Blecher K, Sanchez D, Tuckman-Vernon C, Gialanella P, Friedman JM, et al. Susceptibility of Gram-positive and -negative bacteria to novel nitric oxide-releasing nanoparticle technology. Virulence 2011;2:217-21.
[65] Matsuzaki S, Rashel M, Uchiyama J, Sakurai S, Ujihara T, Kuroda M, et al. Bacteriophage therapy: a revitalized therapy against bacterial infectious diseases. Journal of Infection and Chemotherapy 2005;11:211-9.

[66] Boles BR, Horswill AR. agr-mediated dispersal of Staphylococcus aureus biofilms. PLoS Pathogens 2008;4:e1000052.

[67] O'Grady NP, Alexander M, Burns LA, Dellinger EP, Garland J, Heard SO, et al. Healthcare Infection Control Practices Advisory Committee. Guidelines for the prevention of intravascular catheter-related infections. American Journal of Infection Control 2011;39(4 Suppl. 1):S1-34.

[68] Gudiol F, Aguado JM, Pascual A, Pujol M, Almirante B, Miró JM, et al. Consensus document for the treatment of bacteremia and endocarditis caused by methicillin-resistant Staphylococcus aureus. Sociedad Española de Enfermedades Infecciosas y Microbiología Clínica. Enfermedades Infecciosas y Microbiologia Clinica 2009;27:105-15 [in Spanish].

[69] Zingg W, Sandoz L, Inan C, Cartier V, Clergue F, Pittet D, et al. Hospital-wide survey of the use of central venous catheters. Journal of Hospital Infection 2011;77:304-8

[70] Zingg W. Central venous catheter-associated infections. Best Practice and Research Clinical Anaesthesiology 2008;22:407-21.

[71] van der Kooi TI, Wille JC, van Benthem BH. Catheter application, insertion vein and length of ICU stay prior to insertion affect the risk of catheter-related bloodstream infection. Journal of Hospital Infection 2012;80:238-44.

[72] Goetz AM, Wagener MM, Miller JM, Muder RR. Risk of infection due to central venous catheters: effect of site of placement and catheter type. Infection Control and Hospital Epidemiology 1998;19:842-5.

[73] Parienti JJ, Thirion M, Mégarbane B, Souweine B, Ouchikhe A, Polito A, et al. Members of the Cathedia Study Group. Femoral vs jugular venous catheterization and risk of nosocomial events in adults requiring acute renal replacement therapy: a randomized controlled trial. Journal of the American Medical Association 2008;299:2413-22.

[74] Merrer J, De Jonghe B, Golliot F, Lefrant JY, Raffy B, Barre E, et al., French Catheter Study Group in Intensive Care. Complications of femoral and subclavian venous catheterization in critically ill patients: a randomized controlled trial. Journal of the American Medical Association 2001;286:700-7.

[75] Coopersmith CM, Rebmann TL, Zack JE, Ward MR, Corcoran RM, Schallom ME, et al. Effect of an education program on decreasing catheter-related bloodstream infections in the surgical intensive care unit. Critical Care Medicine 2002;30:59-64

[76] Eggimann P, Harbarth S, Constantin MN, Touveneau S, Chevrolet JC, Pittet D. Impact of a prevention strategy targeted at vascular-access care on incidence of infections acquired in intensive care. Lancet 2000;355:1864-8.

[77] Storti M. Does the use of a polyurethane patch in the CVC dressing further reduce the risk of infection compared with sterile gauze dressing? Infez Med 2011;19:67-73 [in Italian].

[78] Berenholtz SM, Pronovost PJ, Lipsett PA, Hobson D, Earsing K, Farley JE, et al. Eliminating catheter-related bloodstream infections in the intensive care unit. Critical Care Medicine 2004;32:2014-20.

[79] Soifer NE, Borzak S, Edlin BR, Weinstein RA. Prevention of peripheral venous catheter complications with an intravenous therapy team: a randomized controlled trial. Archives of Internal Medicine 1998;158:473-7.

[80] Hawes ML. A proactive approach to combating venous depletion in the hospital setting. Journal of Infusion Nursing 2007;30:33-44.

[81] Yilmaz G, Caylan R, Aydin K, Topbas M, Koksal I. Effect of education on the rate of and the understanding of risk factors for intravascular catheter-related infections. Infection Control and Hospital Epidemiology 2007;28:689-94.

[82] Maki DG, Ringer M. Evaluation of dressing regimens for prevention of infection with peripheral intravenous catheters. Gauze, a transparent polyurethane dressing, and an iodophor-transparent dressing. Journal of the American Medical Association 1987;258:2396-403.

[83] Frasca D, Dahyot-Fizelier C, Mimoz O. Prevention of central venous catheterrelated infection in the intensive care unit. Critical Care 2010;14:212.

[84] Mermel LA. Prevention of intravascular catheter-related infections. Annals of Internal Medicine 2000;132:391-402.

[85] Maki DG, Stolz SM, Wheeler S, Mermel LA. Prevention of central venous catheter-related bloodstream infection by use of an antiseptic-impregnated catheter. A randomized, controlled trial. Annals of Internal Medicine 1997; 127:257-66.

[86] Rupp ME, Lisco SJ, Lipsett PA, Perl TM, Keating K, Civetta JM, et al. Effect of a second-generation venous catheter impregnated with chlorhexidine and silver sulfadiazine on central catheter-related infections: a randomized, controlled trial. Annals of Internal Medicine 2005;143:570-80.

[87] Brun-Buisson C, Doyon F, Sollet JP, Cochard JF, Cohen Y, Nitenberg G. Prevention of intravascular catheter-related infection with newer chlorhexidine silver sulfadiazine-coated catheters: a randomized controlled trial. Intensive Care Medicine 2004;30:837-43.

[88] Veenstra DL, Saint S, Saha S, Lumley T, Sullivan SD. Efficacy of antisepticimpregnated central venous catheters in preventing catheter-related bloodstream infection: a meta-analysis. Journal of the American Medical Association 1999;281:261-7.

[89] Raad I, Reitzel R, Jiang Y, Chemaly RF, Dvorak T, Hachem R. Anti-adherence activity and antimicrobial durability of anti-infective-coated catheters against multidrug-resistant bacteria. Journal of Antimicrobial Chemotherapy 2008;62:746-50.

[90] Marik PE, Abraham G, Careau P, Varon J, Fromm Jr RE. The ex vivo antimicrobial activity and colonization rate of two antimicrobial-bonded central venous catheters. Critical Care Medicine 1999;27:1128-31. 
[91] Ramos ER, Reitzel R, Jiang Y, Hachem RY, Chaftari AM, Chemaly RF, et al. Clinical effectiveness and risk of emerging resistance associated with prolonged use of antibiotic-impregnated catheters: more than 0.5 million catheter days and 7 years of clinical experience. Critical Care Medicine 2011;39:245-51.

[92] Tambe SM, Sampath L, Modak SM. In vitro evaluation of the risk of developing bacterial resistance to antiseptics and antibiotics used in medical devices. Journal of Antimicrobial Chemotherapy 2001;47:589-98.

[93] Sampath LA, Tambe SM, Modak SM. In vitro and in vivo efficacy of catheters impregnated with antiseptics or antibiotics: evaluation of the risk of bacterial resistance to the antimicrobials in the catheters. Infection Control and Hospital Epidemiology 2001;22:640-6.

[94] Lorente L, Lecuona M, Ramos MJ, Jiménez A, Mora ML, Sierra A. Lower associated costs using rifampicin-miconazole-impregnated catheters compared with standard catheters. American Journal of Infection Control 2011;39:895-7.

[95] Marciante KD, Veenstra DL, Lipsky BA, Saint S. Which antimicrobial impregnated central venous catheter should we use? Modelling the costs and outcomes of antimicrobial catheter use. American Journal of Infection Control 2003;31:1-8.

[96] Shorr AF, Humphreys CW, Helman DL. New choices for central venous catheters: potential financial implications. Chest 2003;124:275-84.

[97] Hagau N, Studnicska D, Gavrus RL, Csipak G, Hagau R, Slavcovici AV. Central venous catheter colonization and catheter-related bloodstream infections in critically ill patients: a comparison between standard and silver-integrated catheters. European Journal of Anaesthesiology 2009;26:752-8.

[98] Yahav D, Rozen-Zvi B, Gafter-Gvili A, Leibovici L, Gafter U, Paul M. Antimicrobial lock solutions for the prevention of infections associated with intravascular catheters in patients undergoing hemodialysis: systematic review and meta-analysis of randomized, controlled trials. Clinical Infectious Diseases 2008;47:83-93.

[99] Fortún J, Grill F, Martín-Dávila P, Blázquez J, Tato M, Sánchez-Corral J, et al. Treatment of long-term intravascular catheter-related bacteraemia with antibiotic-lock therapy. Journal of Antimicrobial Chemotherapy 2006;58:816-21.

[100] Stone PW. Economic burden of healthcare-associated infections: an American perspective. Expert Review of Pharmacoeconomics \& Outcomes Research 2009;9:417-22.
[101] Rosenthal VD, Maki DG, Salomao R, Moreno CA, Mehta Y, Higuera F, et al. Device-associated nosocomial infections in 55 intensive care units of 8 developing countries. International Nosocomial Infection Control Consortium. Annals of Internal Medicine 2006;145:582-91.

[102] Klevens RM, Morrison MA, Nadle J, Petit S, Gershman K, Ray S, et al. Invasive methicillin-resistant Staphylococcus aureus infections in the United States. Journal of the American Medical Association 2007;298:1763-71.

[103] Saint S, Veenstra DL, Lipsky BA. The clinical and economic consequences of nosocomial central venous catheter-related infection: are antimicrobial catheters useful? Infection Control and Hospital Epidemiology 2000;21: 375-80.

[104] Hockenhull JC, Dwan K, Boland A, Smith G, Bagust A, Dündar Y, et al. The clinical effectiveness and cost-effectiveness of central venous catheters treated with anti-infective agents in preventing bloodstream infections: a systematic review and economic evaluation. Health Technology Assessment 2008;12:iii-v. xi-xii.

[105] O'Grady NP, Alexander M, Dellinger EP, Gerberding JL, Heard SO, Maki DG et al. Guidelines for the prevention of intravascular catheter-related infections. Centers for Disease Control and Prevention. MMWR - Recommendations and Reports 2002;51:1-29.

[106] Tacconelli E, Smith G, Hieke K, Lafuma A, Bastide P. Epidemiology, medical outcomes and costs of catheter-related bloodstream infections in intensive care units of four European countries: literature- and registry-based estimates. Journal of Hospital Infection 2009;72:97-103.

[107] Maki DG, Kluger DM, Crnich CJ. The risk of bloodstream infection in adults with different intravascular devices: a systematic review of 200 published prospective studies. Mayo Clinic Proceedings 2006;81:1159-71.

[108] Tarricone R, Torbica A, Franzetti F, Rosenthal VD. Hospital costs of central line-associated bloodstream infections and cost-effectiveness of closed vs. open infusion containers. The case of intensive care units in Italy. Cost Effectiveness and Resource Allocation 2010;8:8. http://www.resource-allocation.com/content/8/1/8 [accessed 15.03.13].

[109] Harbarth S, Sax H, Gastmeier P. The preventable proportion of nosocomial infections: an overview of published reports. Journal of Hospital Infection 2003;54:258-66. 